TECHNICAL NOTES AND MANUALS

\title{
A New Tool for Distributional Incidence Analysis: An Application to Fuel Subsidy Reform
}

Prepared by Stefania Fabrizio, Alexei Goumilevski and Kangni Kpodar Fiscal Affairs Department

I N TER N A T I O NAL MONETARY FUND 


\section{TECHNICAL NOTES AND MANUALS}

\section{A New Tool for Distributional Incidence Analysis: An Application to Fuel Subsidy Reform ${ }^{1}$}

\section{EXECUTIVE SUMMARY}

Increased focus on income inequality and distributional issues has made incidence analysis a crucial input into policy decisions. This note presents the theoretical framework used to conduct incidence analysis of fuel price subsidy reform and presents a user-friendly tool for its application. This new tool requires limited inputs and has the advantage of using the commonly available software program Excel. The note presents an illustration based on the case of Brazil, using the 2005 household survey and input-output table. The results reinforce the typical finding that fuel subsidies benefit well-off households and that their removal would be progressive.

\footnotetext{
${ }^{1}$ The authors are grateful to David Coady for insightful comments and suggestions, and thank IMF staff for useful feedback. Louis Sears provided excellent research assistance. Liza Prado and Ana Popovich provided invaluable administrative assistance.
} 


\section{CONTENTS}

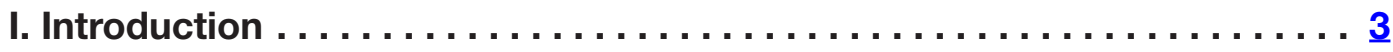

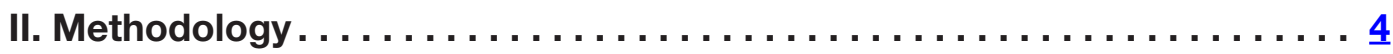

A. Theoretical framework ...........................

B. A new tool for distributional incidence analysis $\ldots \ldots \ldots \ldots \ldots \ldots \ldots \ldots \ldots \ldots \ldots \ldots \ldots$

III. Illustrative country-case study: Brazil. .................. 10

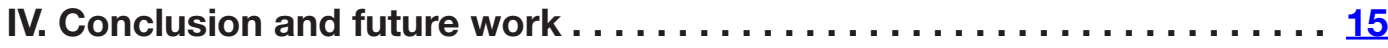

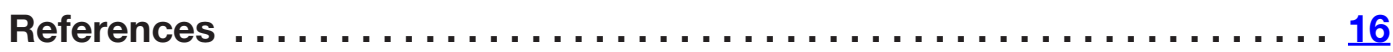

Figures

1. Template for Distributional Analysis of Fuel Subsidy Reform: "Input" Tab . . . . . . . . 7

2. Template for Distributional Analysis of Fuel Subsidy Reform: "Mapping" Tab. . . . . . . 7

3. Template for Distributional Analysis of Fuel Subsidy Reform: "Run" Tab . . . . . . . . 9

4. Dialog Box for Fuel Product Cost Shares in Intermediate Consumption . . . . . . . . . . 9

5. Brazil: International and Domestic Prices for Gasoline and Diesel,

Jan $2004-\operatorname{Dec} 2014$. . . . . . . . . . . . . . . . . . . . . . . . . . . . . . 11

6. Fuel Budget Shares, Direct Subsidy Shares and Direct Welfare Impact of

Fuel Price Increase . . . . . . . . . . . . . . . . . . . . . . . 13

7. Indirect Subsidy Shares, Price Changes in Other Sectors, and Indirect Welfare Impact . . . . . . . . . . . . . . . . . . . . . .

8. Distribution of Total Welfare Impact, Subsidy Shares and

First-round Effect on Price Level. . . . . . . . . . . . . . . . . . . . . . . . . . . . . . . . . 14 


\section{INTRODUCTION}

Although the recent decline in international oil prices has led to a reduction in fuel subsidies, post-tax subsidies remain significant in many countries. Pre-tax subsidies arise when fuel prices paid by households and firms_-for final or intermediate consumption—are below supply costs. Post-tax subsidies, which have been estimated globally at US $\$ 5.3$ trillion in 2015 (6.5 percent of global GDP, see Coady et al, 2015), include an adjustment for efficient taxation to reflect both revenue needs and a correction for negative consumption externalities.

There is a broad agreement that the fuel subsidies are inefficient and regressive (Clements et al., 2013; Coady, Flamini and Sears, 2015). Underpriced fuel products distort resource allocation by encouraging excessive fuel consumption, artificially promoting capital-intensive industries, thus discouraging employment creation. Subsidies lead to higher fuel consumption, exerting pressures on the balance of payments of net oil importers, while promoting smuggling to neighboring countries where domestic prices are higher. Moreover, the fiscal burden of fuel subsidies is generally high and can crowd out education, health and other social expenditures that are critical for growth and poverty reduction. Finally, the benefits of fuel subsidies are consistently captured by higherincome households, in particular in developing countries, thus widening existing income inequalities. The adverse effect on income inequalities can in turn reinforce the economic growth cost of fuel subsidies (see Berg and Ostry, 2011).

Concern about the potential impact of the removal of fuel subsidies on low-income households has been a barrier to energy subsidy reforms in many countries. This highlights the importance of assessing the welfare impact of fuel price changes and their distribution across income groups. Evidence on the distributional impact of fuel subsidy reform constitutes a crucial input into policy decisions, including how best to protect the most vulnerable from the reform.

The impact of changes in fuel prices on the welfare of households occurs through direct and indirect channels. The direct impact arises when households purchase fuel products for cooking, heating, lighting, and private transport. The indirect impact arises when households purchase goods and services that are produced using fuel products. The magnitude of the direct and indirect impacts depends on the share of cooking, lighting, heating, and private transport in total household consumption as well as on the fuel intensity of other goods and services. The distribution of the impacts across income groups will depend on the relative importance of these factors across income groups. ${ }^{2}$

This paper presents a user-friendly tool relying on an excel-based template to assess the distributional incidence of a fuel subsidy reform. The tool is relatively straightforward to set up, and requires limited inputs on key variables and parameters of the underlying model. Using household survey and input-output table data, the tool provides estimates of the direct and indirect welfare impacts of an increase in fuel prices, the distribution of these impacts across income

\footnotetext{
${ }^{2}$ Fuel price subsidy reforms can induce changes in the pattern of fuel consumption and production (substitution effects), which may, in turn, reduce the overall impact of the reform on household welfare.
} 
groups, the share of fuel subsidies accruing to different income groups, and the price increase in other sectors of the economy following the increase in fuel prices. An application to fuel subsidy reform in Brazil is presented as an illustrative case study.

The rest of the note is structured as follows. Section II reviews the theoretical framework underpinning the analysis of the distributional impact of fuel subsidy reform, and presents the features of the new tool. Section III illustrates an application of the tool using data for Brazil, and Section IV concludes.

\section{METHODOLOGY}

\section{A. Theoretical Framework}

Changes in fuel prices have both direct and indirect impacts on household welfare. This section presents the theoretical framework to assess the magnitude of these two transmission channels. The overall welfare impact is the sum of these direct and indirect impacts calculated at the household level and then averaged by income groups (quintiles or deciles) to gauge the distributional incidence of fuel price changes.

\section{Direct welfare impact}

Assuming demand is unchanged, the money measure of the direct loss in welfare-or decrease in real income, a proxy for household welfare-from a price increase of a fuel product is a function of its budget share (Coady and Newhouse, 2006). The formula for the direct welfare impact is as follows:

$$
\frac{d Y_{d i r}}{Y}=b_{i} \frac{d P_{i}}{P_{i}}
$$

where $\frac{d Y_{\text {dir }}}{Y}$ is the percentage change in household welfare or real income $Y, b_{i}$ is the share of spending on fuel product $i$ in total household expenditure, and $\frac{d P_{i}}{P_{i}}$ is the percentage change in the price of fuel product $i$.

For instance, if diesel accounts for 10 percent of total spending of a household, the direct welfare impact of a 10 percent increase in the diesel price would be a 1 percent decline in household welfare. For more than one fuel product, the equation above becomes:

$$
\frac{d Y_{d i r}}{Y}=\sum_{i=1}^{m} b_{i} \frac{d P_{i}}{P_{i}}
$$

where $m$ is the total number of fuel products. 


\section{Indirect welfare impact}

Similar to the direct welfare impact, the formula for the indirect welfare impact is also a function of the budget shares of non-fuel goods and services as follows:

$$
\frac{d Y_{\text {ind }}}{Y}=\sum_{j=1}^{n} b_{j} \frac{d P_{j}}{P_{j}}
$$

where $\frac{d Y_{\text {ind }}}{Y}$ is the percentage change in household welfare associated with the indirect effect of fuel price changes; $b_{j}$ is the budget share of a good or a service $j$ consumed by households other than fuel products; $\frac{d P_{j}}{P_{j}}$ the corresponding price change of these goods and services following the change in fuel prices; and $\mathrm{n}$ is the total number of non-fuel goods and services.

The price-shifting model developed in Coady and Newhouse (2006) is used to estimate the impact of fuel price increases on the prices of the goods and services that are produced using fuel products $\left(\frac{d P_{j}}{P_{j}}\right.$ above). The technology of production is captured by an input-output coefficient matrix A, with $a_{i j}$ denoting the cost of input $i$ in producing one unit of output $j$. This implies a Leontief production function, where the firm's demand for inputs is assumed not to be affected by changes in input prices. A simplified version of this model with two categories of sectors, the controlled sectors (fuel) and the non-controlled sectors (all others), is given by the following formula: ${ }^{3}$

$$
\Delta P_{n c}=\Delta P_{c} *(I-A)^{-1}
$$

where $\Delta P_{n c}$ is a row vector of the price changes for other goods and services, $\Delta P_{c}$ is a row vector of the price changes in fuel products, and $\mathrm{A}$ is the input-output coefficient matrix. ${ }^{4}$

The price-shifting model relies on a number of assumptions. It assumes that factor prices are constant and the only exogenous price changes $\Delta \boldsymbol{P}_{\boldsymbol{c}}$ are in the petroleum sector. Also, the model does not take into account changes in consumption behavior and as such it provides an upperbound of the welfare impact. In the same vein, it does not capture changes to the production structure in response to fuel price increases, for instance due to improvements in fuel efficiency.

\section{B. A New Tool For Distributional Incidence Analysis}

The new tool for analyzing the distributional impact of fuel price subsidies is based on the model discussed above. It is built using Excel and presented as a template with input sheets to facilitate the identification of the main variables and parameters of the model, and produce the results in a graphic representation and tables. The template is user friendly, ${ }^{5}$ requires limited

\footnotetext{
${ }^{3}$ In the non-controlled sectors, an increase in production cost is pushed fully through to output prices, whereas in the controlled sectors, output prices would not change in response to higher production costs as prices are controlled by the government.

${ }^{4}$ When the controlled sectors include non-fuel sectors (for instance education and health), the formula is slightly different (see Coady and Newhouse, 2006, for more details).

${ }^{5}$ The template is available at http://www.imf.org/external/np/fad/subsidies/data/exceltemplate.zip. A video tutorial and an application are available in the IMF online course on energy subsidy reform (https://www.edx.org/course/energysubsidy-reform-imfx-esrx-0).
} 
inputs, and does not need expensive software, which are key advantages over existing tools (such as Coady and Newhouse, 2006; and Araar and Verme, 2012). ${ }^{6}$

The data required are a household survey database and an input-output matrix. The household survey database should contain data on household characteristics (size, sampling weight, location, and total expenditure) and household consumption broken down by numerous categories of goods and services. For fuel products, household consumption for each fuel product is desirable. The input-output matrix is derived from an input-output table by calculating the share of different inputs in the production cost structure of each sector.

Setting up and running the template requires four steps (instructions are also available on the "Read me" sheet and on individual sheets in the template):

(1) On the "Input" tab, specify the path to the household database and input-output matrix files and upload them in the template (see top panel, Figure 1). This step will generate drop-down lists to facilitate the selection of the key variables required to run the simulations.

(2) On the same tab, select the variables in the household database containing household consumption of fuel products, and indicate the price changes to be simulated (2nd panel, Figure 1). Then, specify if the survey data are at the household level or aggregated by income groups (quintiles/deciles) or by a different household grouping (3rd panel, Figure 1 ). ${ }^{7}$ In the former case, proceed to select the variables representing the characteristics of households (4th panel, Figure 1), ${ }^{8}$ and indicate the income groups (quintile/decile) for the distributional analysis (5th panel, Figure 1). Lastly, select the controlled sectors (other than the fuel petroleum sector) from the list of sectors in the input-output matrix (bottom panel, Figure 1). ${ }^{9}$

(3) Move to the "Mapping" tab and assign the different goods and services from the household database to the corresponding sector in the input-output matrix (using the dropdown list) to allow for the calculation of the indirect effect (see Figure 2).

\footnotetext{
${ }^{6}$ The Coady and Newhouse (2006) Stata program files, are available at http://www.imf.org/external/np/fad/subsidies/ data/stataprogram.zip. For the tool developed by Araar and Verme (2012), see http://www.subsim.org/.

${ }^{7}$ It is important to note that when the survey data are at the household level, expenditure data should be in nominal terms (value of goods or services consumed by households). But, when the survey data are aggregated by income groups (quintiles/deciles) or any other groups, the expenditure data in the survey should be the budget shares.

8 If the sampling weights are not provided due to lack of data, the template will run the simulations by weighting equally all households. Also, when the geographical location is not available, the template will produce the results for all households without the breakdown between urban and rural households.

${ }^{9}$ The controlled sectors are those for which prices would be kept unchanged despite the increase in fuel prices. These could include health and education sectors, public administration, and the electricity sector on the assumption that the government regulates user costs in these sectors and would unlikely pass on the higher cost of the fuel price increases.
} 
Figure 1. Template for Distributional Analysis of Fuel Subsidy Reform: "Input" Tab

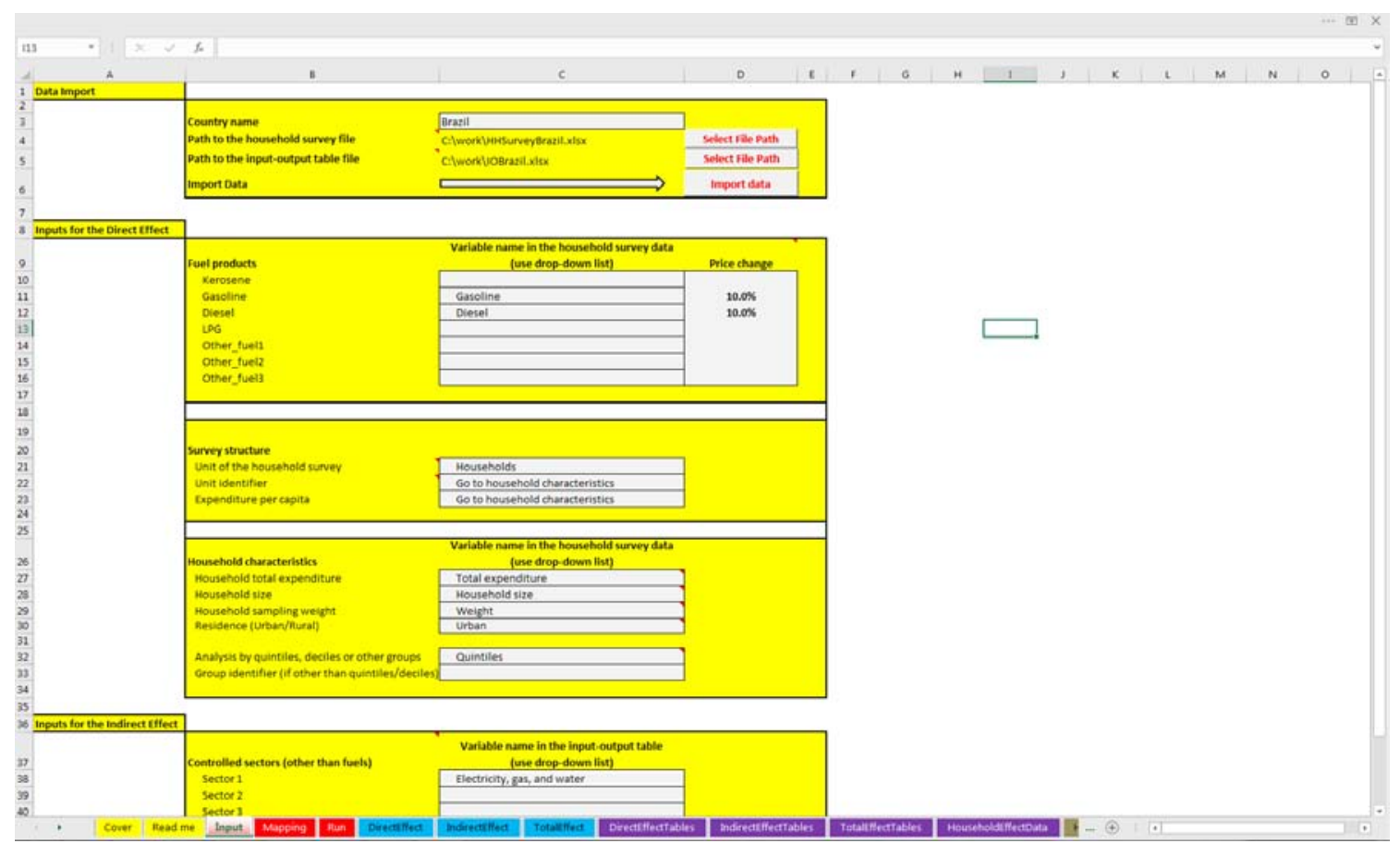

Figure 2. Template for Distributional Analysis of Fuel Subsidy Reform: "Mapping" Tab

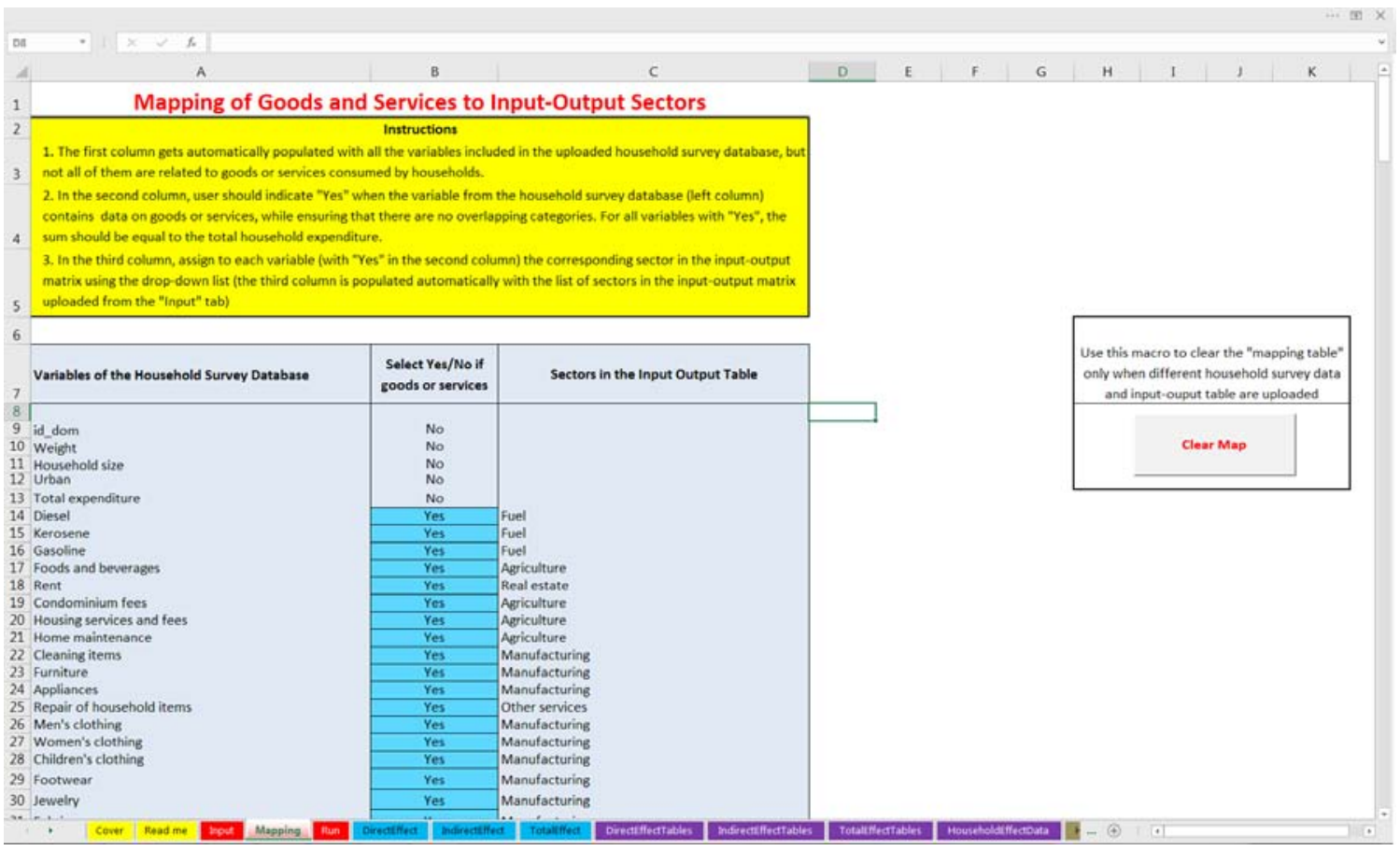


(4) On the "Run" tab, run the macro to compute the welfare impact and get the results for the direct, indirect and total welfare impacts of the simulated price increases (Figure 3). There is also an individual macro to run each of the welfare impacts. In particular the macro for the direct welfare impact can be useful when an input-output matrix is not available (see below). Depending on the composition of the fuel sector, the template may need additional parameters. Three cases can arise:

- Each fuel product appears as a separate sector in the input-output table. This is the ideal case, but unfortunately exists only for a very few countries, mainly advanced economies. The template would not require any additional information.

- The input-output table features a composite sector for fuel products. The user needs to input the share of each fuel product in intermediate consumption to calculate the average increase in fuel prices (Figure 4a). By default, it is assumed that diesel is the only fuel product used for intermediate consumption, but this could be changed if country-specific data are available.

- The fuel sector in the input-output is mixed with utilities such as electricity and water. The user will be prompted to indicate the share of fuel products in the production of the aggregate sector (Figure 4b), ${ }^{10}$ and then the share of each fuel product in intermediate consumption of fuels.

\section{The main outputs of the template include the following: ${ }^{11}$}

- The direct welfare impact of fuel price increases on each income group with the breakdown by fuel products, which gives a picture on how various income groups are affected differently depending on the fuel product subject to the price increase.

- The share of direct fuel subsidies accruing to each income group to identify who benefits the most from fuel subsidies. The result is also available separately by fuel product.

- The price increase in the other sectors of the economy resulting from the increase in fuel prices, with the magnitude of the price increase reflecting the energy intensity of the sector. The tool also calculates the distribution of the indirect welfare effect by income group, highlighting the contribution of each sector (for instance, food and transport tend to be the most sensitive sectors to fuel price increases). In addition, the share of indirect fuel subsidies accruing to each income group is calculated to compare the distribution of indirect fuel subsidies to that of the direct fuel subsidies.

- The distribution of the total welfare impact (sum of the direct and indirect impacts) and the subsidy share by income groups are shown, as well as the relative contribution of the direct and indirect effects to the total expenditure effect. Using household consumption weights, the template also calculates the first-round effect of the simulated fuel price increases on consumer price index. ${ }^{12}$

\footnotetext{
${ }^{10}$ No default value is provided, and this parameter is required before the template proceeds with the estimation of the indirect effects.

${ }^{11}$ The screenshots of the outputs are presented in the next section where the results for Brazil are discussed.

12 This is the weighted average of the price increases for fuel and non-fuel products, with the weights being the share of these products in total household expenditure. There may be a second-round effect if the first-round effect leads to wage increases, which in turn put pressure on domestic demand and prices. The second-round effect also depends on the fiscal and monetary policy responses.
} 
Figure 3. Template for Distributional Analysis of Fuel Subsidy Reform: "Run" Tab

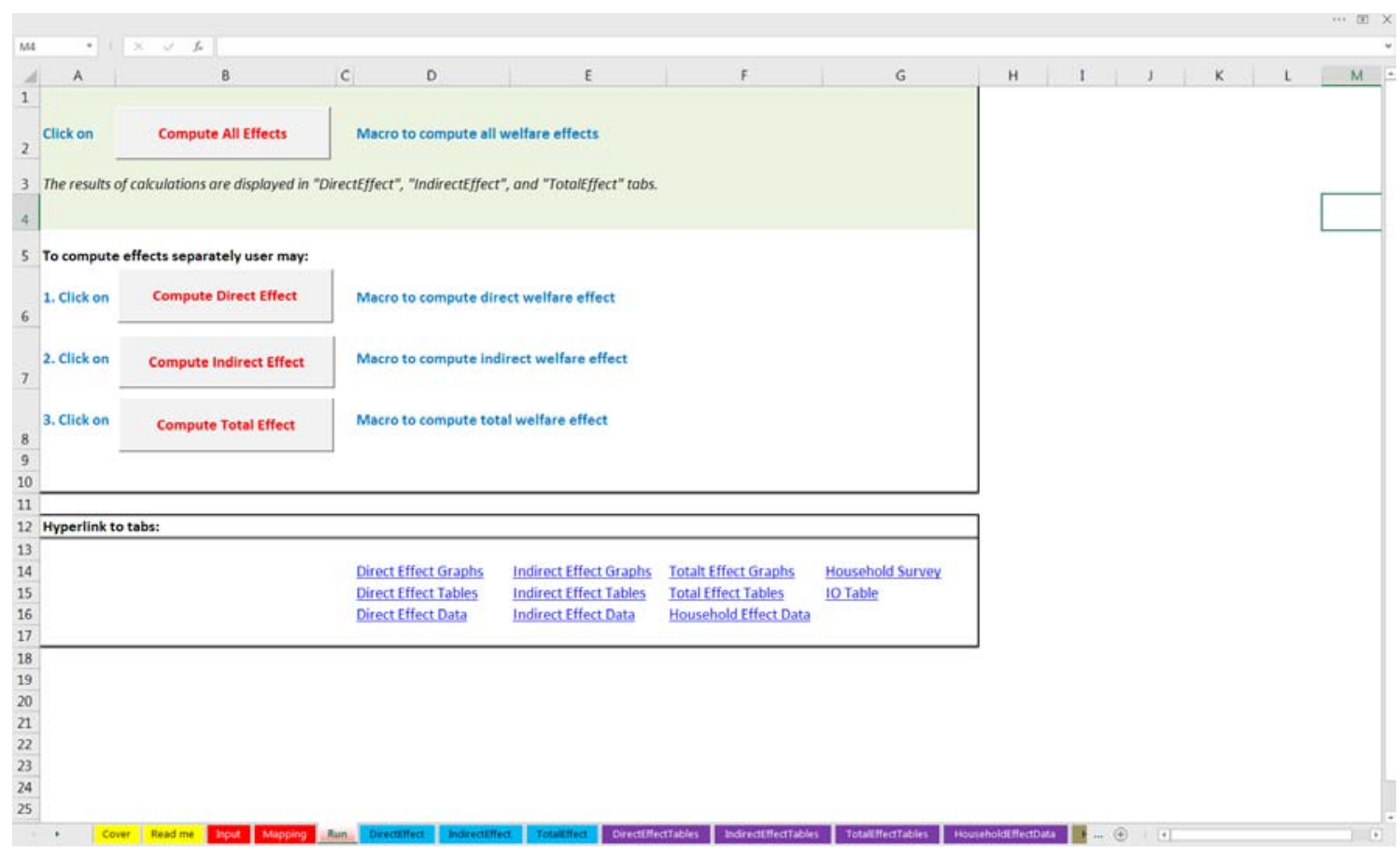

Figure 4. Dialog Box for Fuel Product Cost Shares in Intermediate Consumption

(a) The input-output table features a composite sector for fuel products

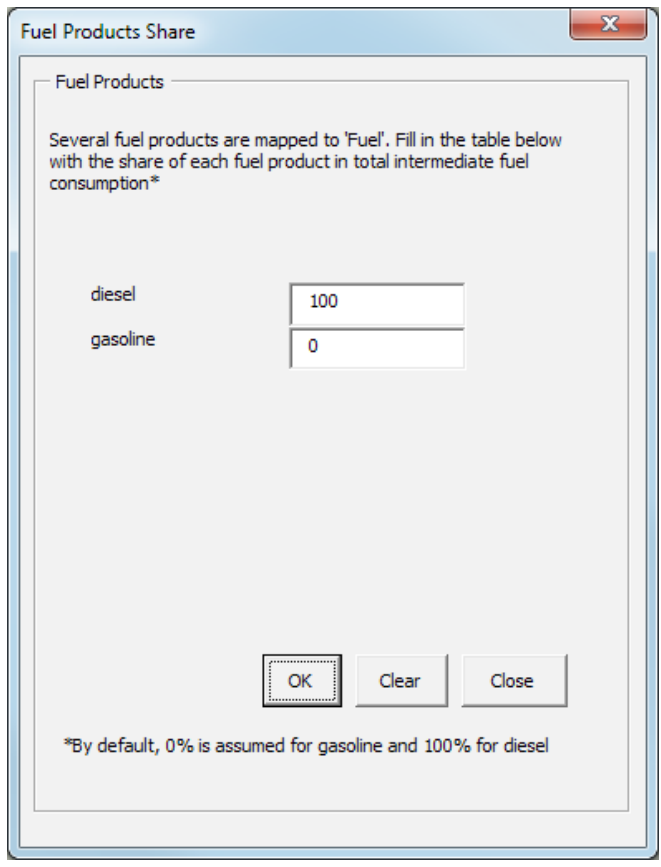

(b) The fuel sector in the input-output is mixed with utilities such as electricity and water

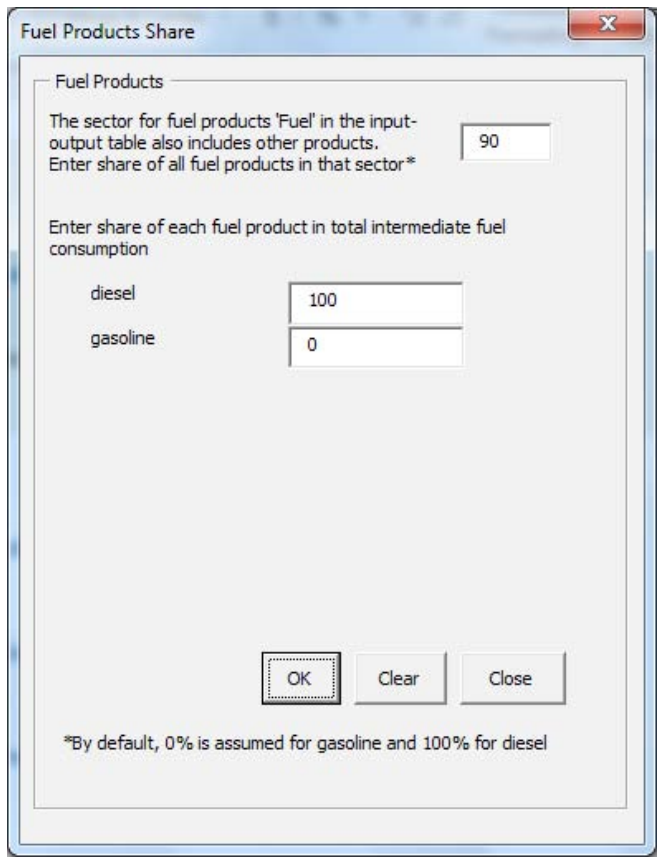


In the absence of an input-output table, the outputs of the template will be restricted to the direct welfare impact. It is common that countries do not have an input-output available, and even when available, the input output table may be outdated and no longer represents a reliable picture of the structure of the economy. The template allows to estimate the direct welfare impact for cases where an input-output table is not available. Among the four steps discussed above, the user should: (i) go through steps 1 and 2 focusing on the aspects related to the household survey data; (ii) skip step 3 , and in step 4 , only the macro pertaining to the direct welfare impact should be executed. An alternative is to use information on indirect effects for similar country, for instance using data from Coady, Flamini, and Sears (2015).

\section{ILLUSTRATIVE COUNTRY-CASE STUDY: BRAZIL}

Three reasons motivate the choice of Brazil as a case study for this illustrative application. First, despite the significant decline in income inequality over the past years, Brazil still has one of the highest income inequality levels in the world. Identifying who benefits from fuel subsidies can offer insights for policy makers looking for options to address income inequality issues. Second, although Brazil exports oil, domestic consumption of fuel remains heavily dependent on fuel imports and has outpaced fuel exports. On the one hand, revenue from oil exports creates incentives to subsidize domestic consumption, while on the other hand, reliance on imports to meet domestic consumption reminds policy makers that fuel subsidies can be extremely costly for the budget and puts pressures on foreign exchange reserves. Finally, a practical reason that guided the choice of Brazil is the availability of a rich household database and an input-output table, a requirement to conduct a comprehensive analysis of the distributional incidence of fuel subsidies.

\section{Background}

Faced with the escalating cost of fuel subsidies, Brazil embarked on a gradual phasing out of fuel subsidies from the 1990s. In the 1980s, the state-owned oil company, Petrobras, had a monopoly in the upstream and downstream petroleum market, and the retail prices were controlled by the government. An oil stabilization fund was set up to cushion the transmission of international oil price volatility to retail prices. However, with rising import costs, the fund was quickly depleted, and accumulated contingent liabilities to Petrobras, which were only partially covered by a budget transfer of 0.8 percent of 1995 GDP in the mid-1990s (Clements et al., 2013), while Petrobras absorbed the remaining loss.

As part of an economy-wide reform agenda, the government started to liberalize fuel prices with the enactment of the 1997 Petroleum law. As a strategy to facilitate the acceptance of reforms, prices for petroleum products consumed by firms were liberalized in the first phases of the reforms (1991-1997), and those for retail consumers were the last; in particular, gasoline, diesel and LPG prices started to be adjusted every three months from 2001. The refinery and downstream sector was opened up to the private sector, putting an end to the monopoly enjoyed 
by Petrobras. Currently, distributors are free to set pump prices, and the ANP (Brazilian National Agency of Petroleum, Natural Gas and Biofuels) is mandated to conduct a periodic price survey for monitoring price behavior and ensuring free competition.

Despite these reforms, Petrobras has remained a dominant player in the market, providing the means to the government-the main shareholder-to indirectly control pump prices. Oliveira and Almeida (2015) point out that since Petrobras owns the bulk of refining capacity in the country and remains the largest fuel importer, the company is in practice responsible for supplying the domestic market and therefore determines domestic prices. Its pricing policy has led to heavy losses in downstream activities, estimated at a cumulative 2.5 percent of GDP during 2011-14.

Figure 5 shows the reemergence of fuel subsidies between 2011 and 2014 as ex-refinery and pump prices failed to keep up with international oil price trends.

Figure 5. Brazil: International and Domestic Prices for Gasoline and Diesel,

Jan 2004-Dec 2014

(Jan 2004=100)
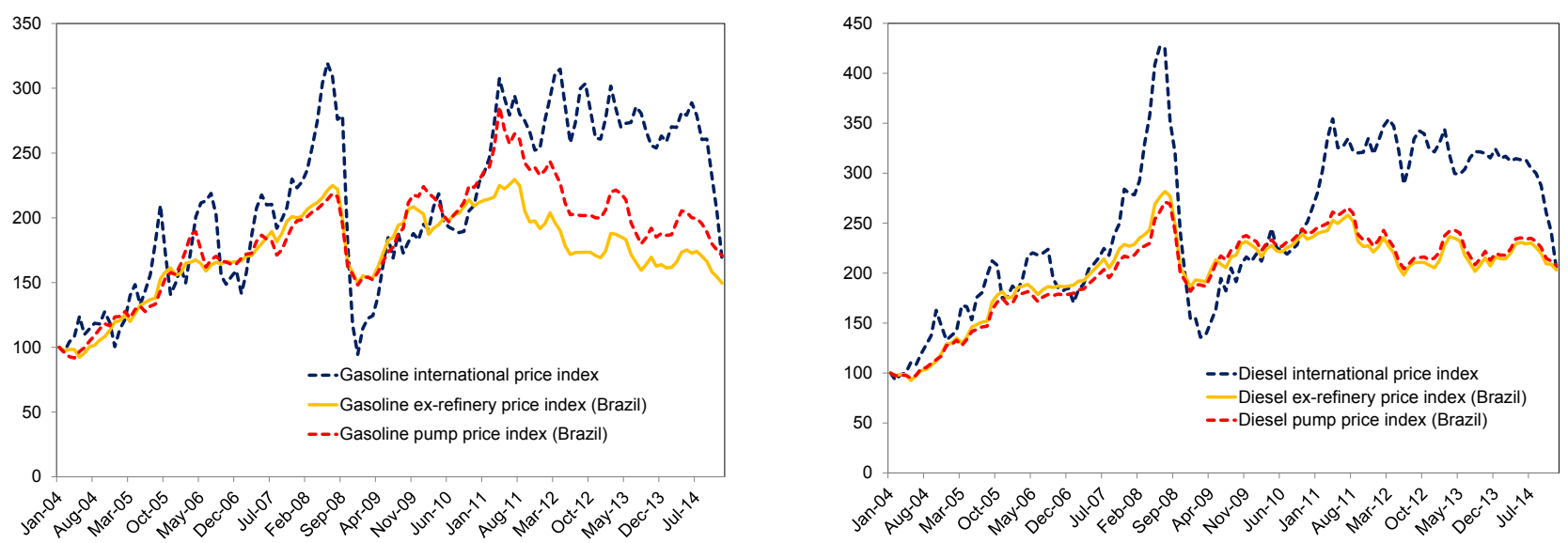

Sources: The Brazilian National Agency of Petroleum, Natural Gas and Biofuels (ANP), IMF and authors' calculations

\section{Results of the simulations}

We simulate a 10 percent increase in gasoline and diesel prices. Household consumption data are provided by the 2005 household survey covering about 56,000 households throughout the country. A condensed version of the 2005 input-output table, covering 13 sectors, was used for the simulations. ${ }^{13}$

The results of the simulations show that the benefits of direct fuel subsidies accrue predominantly to the non-poor (Figure 6). More than half of the direct subsidy on gasoline and

\footnotetext{
${ }^{13}$ The household survey data and the input-output table are provided by the Brazilian Institute of Geography and Statistics (www.ibge.gov.br). In fact, the official aggregated version of the 2005 input-output table includes 12 sectors, but since we need to isolate the fuel sector for the simulation, we used the more disaggregated version of 110 sectors to extract the data for the fuel sector, which is then combined with the 12 sectors of the aggregated version.
} 
diesel is captured by the 20 percent richest households, whereas the poorest quintile receives less than 2 percent of total direct fuel subsidies. This reflects consumption patterns, with the households in the richest quintile allocating 3.6 percent of their spending to fuel products, $4 \frac{1}{2} 2$ times more than those in the poorest quintile. Consequently, the direct welfare impact is progressive as a 10 percent increase in diesel and gasoline prices would lead to a 0.36 percent decline in household welfare for the richest quintile against a 0.08 percent decline for the poorest quintile. On average, the welfare loss associated with the direct welfare effect would be about 0.24 percent. ${ }^{14}$

The indirect welfare impact is comparable across quintiles, but the composition varies (Figure 7). For a 10 percent increase in gasoline and diesel prices, the indirect welfare impact represents about a 0.6 percent decline in household welfare, more or less the same for all quintiles. ${ }^{15}$ This confirms the common finding that the indirect effect tends to be less progressive than the direct effect. Yet, the indirect subsidy share accruing to the richest quintile remains high at about 50 percent, compared to about 6 percent for the lowest quintile. The poorest quintile is more affected by price increases in the agriculture sector (e.g. food products), while price increases of manufactured products predominately affect the richest quintile. Those sectors along with the transport sector are among the most energy-intensive sectors, and hence would experience the largest increases in price following a fuel subsidy reform.

Combining the direct and indirect effects into the total impact suggests that the removal of fuel subsidies is progressive, although rural households would be slightly more affected than urban households (Figure 8). The total welfare impact would be on average 0.34 percent, of which 70 percent is attributable to the direct impact. Further, the bulk of the subsidy accrues disproportionately to well-off households, implying that fuel subsidies are an inefficient and costly way of protecting the poor. Finally, the first-round effect on price level would be mild, with a 10 percent increase in fuel prices leading to an increase in price level by slightly less than 1 percent.

\footnotetext{
${ }^{14}$ Since diesel is not widely consumed by households in Brazil, the direct effect is correspondingly small.

${ }^{15}$ We assumed two controlled sectors: (i) electricity, gas and water, and (ii) public administration, health and education services.
} 
Figure 6. Fuel Budget Shares, Direct Subsidy Shares, and Direct Welfare Impact of Fuel Price Increase

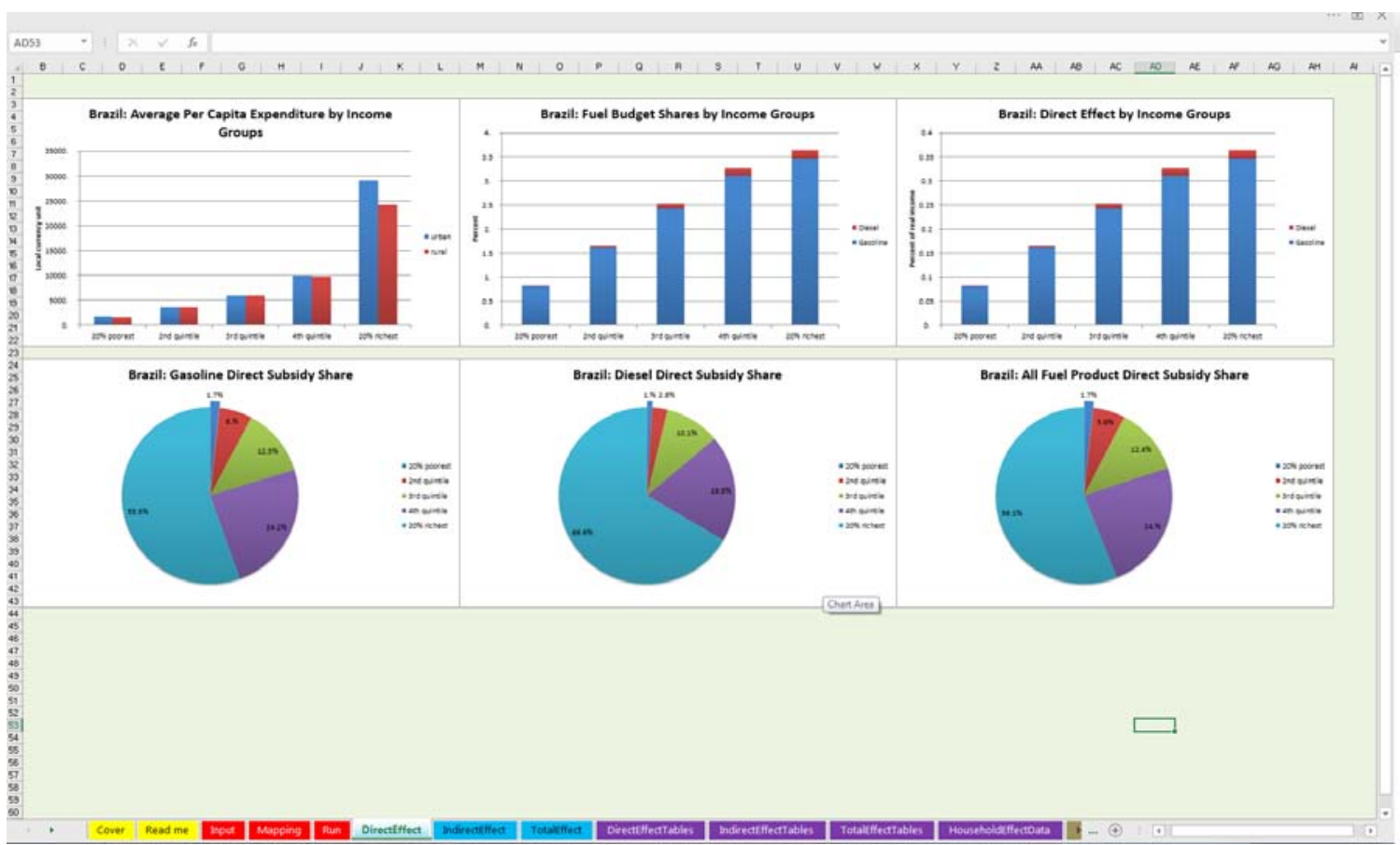

Figure 7. Indirect Subsidy Shares, Price Changes in Other Sectors, and Indirect Welfare Impact

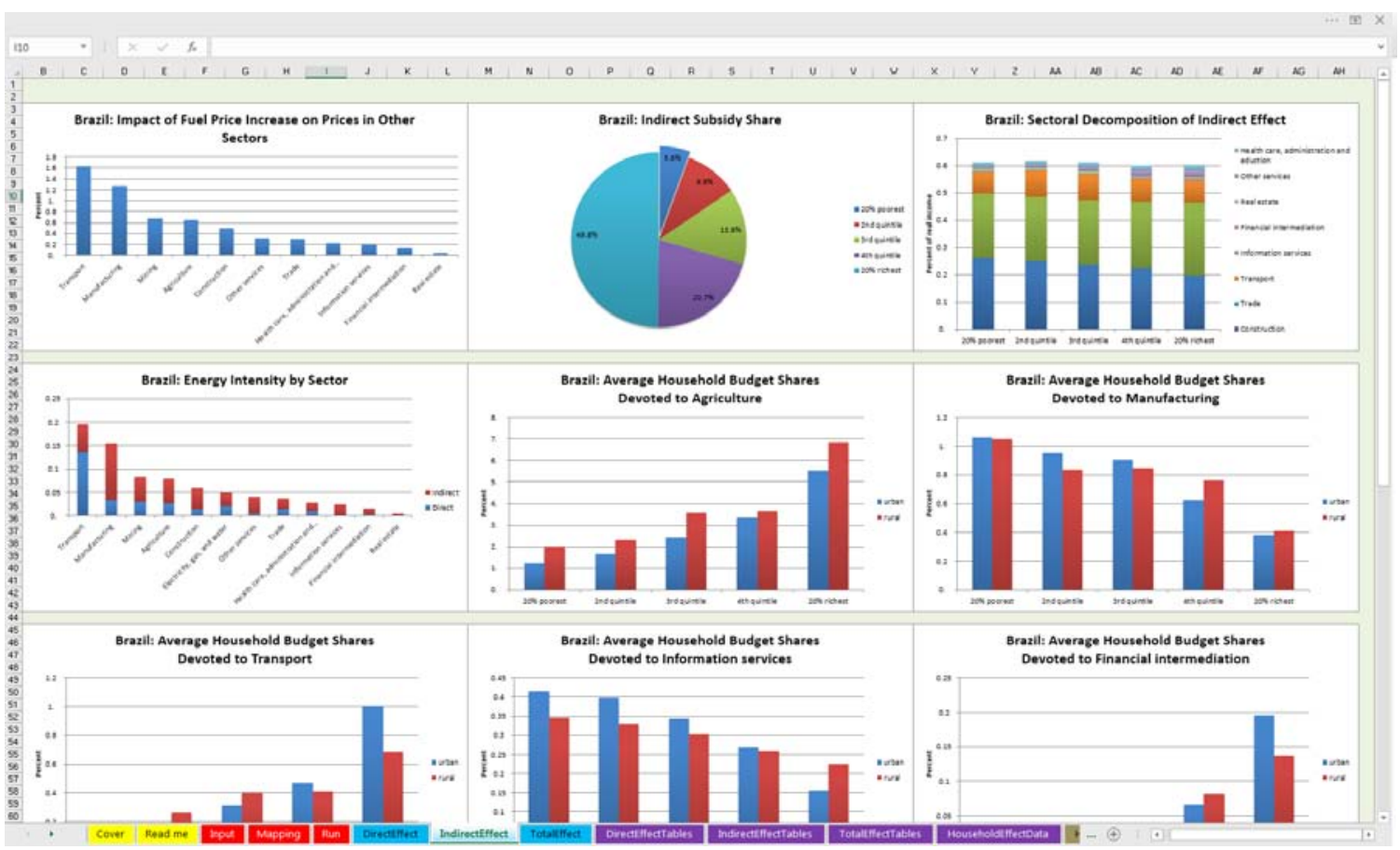


Figure 8. Distribution of Total Welfare Impact, Subsidy Shares and First-round Effect on Price Level

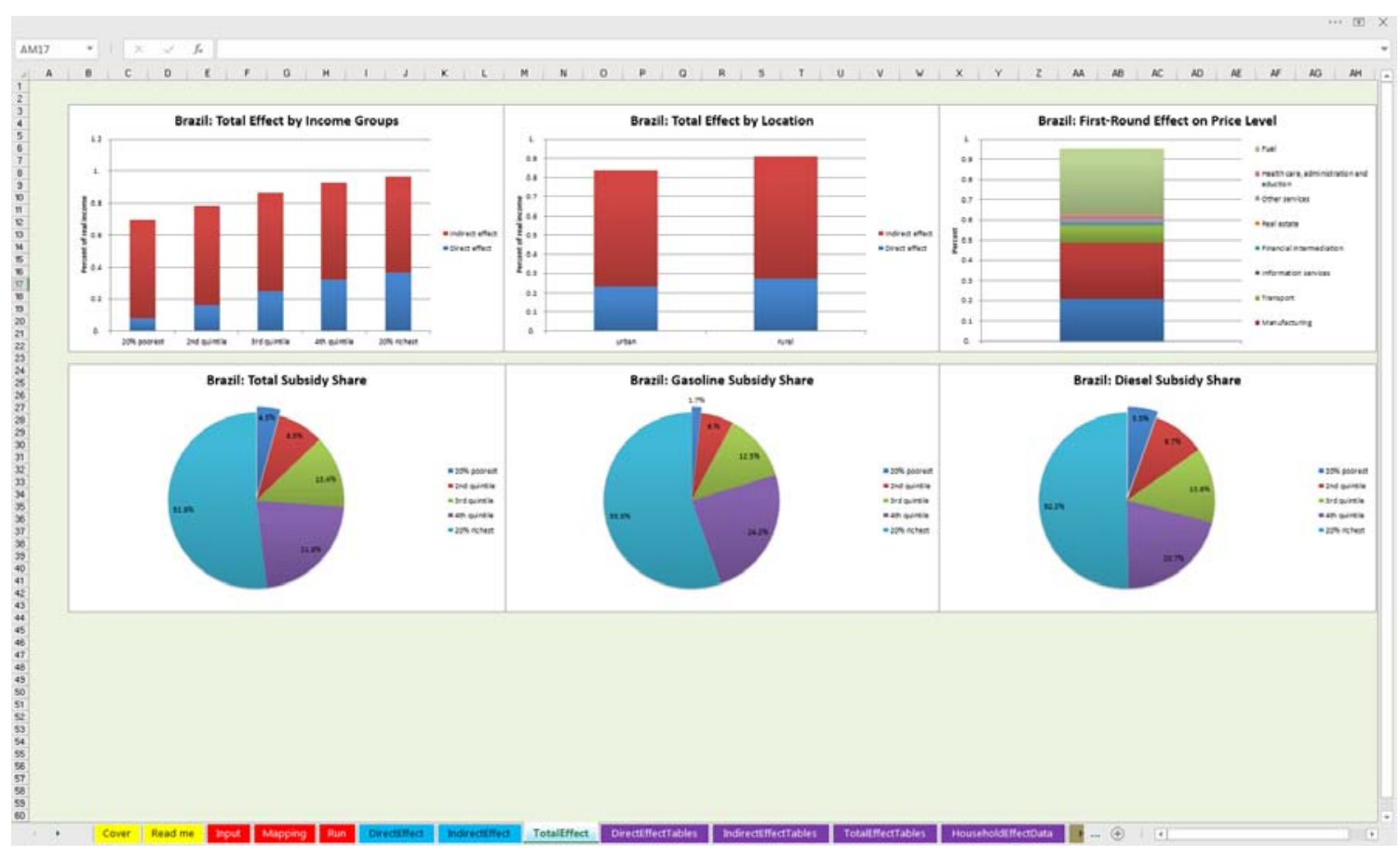




\section{CONCLUSION AND FUTURE WORK}

This note presents an easy and user-friendly tool for conducting incidence analysis of fuel price subsidy reform to facilitate the assessment of the impact of fuel price subsidy reforms on households and economic sectors. Based on the theoretical framework by Coady and Newhouse (2006), the new tool improves on existing ones as it requires limited inputs, relies on excel, and is easy to use. Basic data requirements include a household survey data and an inputoutput table. The tool enables users to analyze the distribution of the impact of fuel price subsidy reform in its various aspects including: the distribution of the direct, indirect, and total welfare impacts across income groups (quintiles or deciles); the share of fuel subsidies accruing to each income group (associated with the direct, indirect, and total welfare impact); the price implications for other economic sectors along with their energy intensity; and the first-round effect on consumer price index. The analysis provides upper bound estimations of the fuel price changes as it does not take into account possible changes in consumption and production patterns.

An application to Brazil data suggests that fuel subsidies are unequally distributed, with the richest quintile receiving about half of total subsidies compared to less than 2 percent for the poorest quintile. An increase in 10 percent of gasoline and diesel prices is estimated to have a modest impact on household welfare (a 0.34 percent decline on average) and price level (an increase of about 1 percent). Overall, the removal of fuel subsidies is progressive as the welfare impact increases significantly with income level.

Next steps for further extension of the tool could include expanding the template to analyze the distributional impact of (1) reforms of food and fertilizer prices; (2) reform of public utility tariff structure for electricity and water; and (3) tax policy reforms, in particular consumption taxes (see Coady, 2006). 


\section{References}

Araar, Abdelkrim, and Paolo Verme, 2012, "Reforming Subsidies: A Tool-Kit for Policy Simulations," Policy Research Working Paper Series 6148, The World Bank.

Berg, Andrew, and Jonathan Ostry, 2011, "Inequality and Unsustainable Growth: Two Sides of the Same Coin?," IMF Staff Discussion Notes 11/08, Washington: International Monetary Fund.

Clements, Benedict, David Coady, Stefania Fabrizio, Sanjeev Gupta, Trevor Serge Coleridge Alleyne, and Carlo A. Sdralevich, eds., 2013. Energy Subsidy Reform: Lessons and Implications. Washington: International Monetary Fund

Coady, David, 2006, "Indirect Tax and Public Pricing Reforms," in Analyzing the Distributional Impact of Reforms: A Practitioner's Guide to Pension, Health, Labor Market, Public Sector Downsizing, Taxation, Decentralization and Macroeconomic Modeling, A. Coudouel and S. Paternostro (eds.). Washington: World Bank.

Coady, David, and David Newhouse, 2006 "Ghana: Evaluating the Fiscal and Social Costs of Increases in Domestic Fuel Prices," in Poverty and Social Impact Analysis of Reform, Coudouel, A., A. Dani and S. Paternostro (eds.). Washington: World Bank.

Coady, David, Ian W.H. Parry, Louis Sears, and Baoping Shang, 2015, "How Large are Global Energy Subsidies?," IMF Working Papers No. 15/105, Washington: International Monetary Fund.

Coady, David, Valentina Flamini, and Louis Sears, 2015, "The Unequal Benefits of Fuel Subsidies Revisited: Evidence for Developing Countries," IMF Working Paper No. 15/250, Washington: International Monetary Fund.

Oliveira, Patrícia, and Edmar Almeida, 2015, "Determinants of Fuel Price Control in Brazil and Price Policy Options", 5th Latin American Energy Economics Meeting. 
TNM/16/07

International Monetary Fund

Fiscal Affairs Department

700 19th Street NW

Washington, DC 20431

USA

Tel: 1-202-623-8554

Fax: 1-202-623-6073

ISBN: $978-7-47554-674-3$

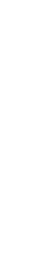

